Article

\title{
Optimal Design and Control of a $z$-Tilt Piezoelectric Based Nano-Scale Compensation Stage with Circular Flexure Hinges
}

\author{
Hau-Wei Lee \\ Center for Measurement Standards, Industrial Technology Research Institute, Hsinchu 300, Taiwan; \\ boomas@ms42.hinet.net; Tel.: +886-958-405199 \\ Academic Editor: Ping-Hei Chen \\ Received: 5 May 2016; Accepted: 5 August 2016; Published: 19 August 2016
}

\begin{abstract}
The Taguchi method is widely used for the optimization of mechanical design and this study is used it in the design of a 2D circular flexure hinge for a $z$-tilt piezoelectric based nano-scale compensation stage. Maximum displacement of the stage is $16 \mu \mathrm{m}$ at $z$-axis and \pm 30 arcsec at $\theta_{x}$ and $\theta_{y}$. The most important design parameters for such a flexure hinge are minimal diameter, body height, and notch radius. The important requirements for the optimal design of a flexure hinge is that the $z$-tilt stage should have the highest possible natural frequency and the smallest coupling displacement. Simulation results show the nano-stage to have a higher natural frequency $(626 \mathrm{~Hz})$ and lower coupling displacement $(0.032 \%)$. A kinematic model for the $z$-tilt stage has also been proposed in this study and the experimental results show the actual natural frequency of $510 \mathrm{~Hz}$ to be slightly lower than in the simulation. By keeping the angular displacement less than \pm 30 arcsec for $z$-tilt motion of the stage, the results of tracking experiments show a coupling displacement of $300 \mathrm{~nm}$ for the $z$-axis and 1 arcsec for $\theta_{x}$ while the $\theta_{y}$ tracked a sine wave of $1 \mathrm{~Hz}$ and an amplitude of 5 arcsec.
\end{abstract}

Keywords: Taguchi; $z$-tilt; stage; optimization; flexure hinge

\section{Introduction}

The important features of a nano- or micro-scale compensation stage are fast response, high positioning resolution, and excellent positioning repeatability. The two most common kinds of nano-scale compensation stage are $x$-y-yaw and $z$-tilt. The $x$-y-yaw stage is like that proposed by Lee et al. [1], and the $z$-tilt stage is like another proposed by Liu et al. [2]. The structure of $z$-tilt stages is usually simpler than that of $x$-y-yaw stages. However, the shape of the flexure hinges in a $z$-tilt stage influences stage bandwidth and coupling displacement more than in an $x$-y-yaw stage. Both types of nano-scale compensation stage can be of a coplanar design. Although, a coplanar stage has many advantages such as small size, a low center of gravity (which means a higher frequency response), low cumulative mechanical setup error and so on, coupling displacement is intensely influencing positioning accuracy [3]. For example, when the stage is moved in the $y$-direction, displacement in the $x$-direction will not be zero. To decrease the coupling displacement, flexure hinges with reduced stiffness should be considered. However, lowering the stiffness of the flexure hinges can also lower the system bandwidth. Design of the flexure hinges should provide for an optimal coupling displacement to stage bandwidth ratio.

A Scott-Russell amplifying mechanism which was employed one-dimensional flexure hinges was analyzed by Chen et al. [4]. Ahuett-Garza et al. conducted a study about large deflection planar compliant mechanisms constructed by one-dimensional flexure hinges which is similar to the Chen's study [5]. In Ahuett-Garza's study, three kinds of one-dimensional flexure hinge were simulated. 
Tian et al. is using adaptive Simpson integration and polynomial approximation techniques to develop the dimensionless empirical equations for three kinds of one-dimensional flexure hinges [6,7]. The results show that the dimension and form of flexure hinges influence the stiffness and rotational precision. Although above research can analyze one-dimensional flexure hinges very well, there are too many parameters that are difficult for analyzing. The Taguchi method can be used to figure out the optimal parameters for such a system without a lot of experimentation and complex mathematical calculation being necessary. Some studies applied the Taguchi method to design the mechanics which are employed in one-dimensional flexure hinges [8-10].

This study used Taguchi to find the optimal design parameters for a two-dimensional flexure hinges of a z-tilt compensation stage. The three motions of the $z$-tilt stage are the linear motion in the $z$-axis, angular motion in the $x\left(\theta_{x}\right)$ and $y\left(\theta_{y}\right)$ axes. The easiest way to achieve $z$-tilt motion is to use three piezoelectric-flexure-hinge modules (PFM) as shown in Figure 1. Here, each PFM consists of a flexure hinge and a piezoelectric actuator. Figure 2 shows a simulation that explains why flexure hinges are needed for a z-tilt stage. The upper one shows the stress concentrated on the piezoelectric actuator and deformation that occurs on the work platform if there is no flexure. This problem can be avoided by the use of flexure hinges. Two kinds of flexure hinge are commonly used, notched and circular [11]. Circular flexure hinges are usually employed on z-tilt stages because motion is two-dimensional. Other kinds of flexure hinges with special shapes have been proposed by Jywe [12]. Flexure hinges are not limited to use on nano-scale stages, but can also be used in such applications as tool compensation as proposed by Andrew Woronko et al. [13]. The main problem of piezoelectric actuator usage is hysteresis which causes low positioning accuracy. For increased positioning accuracy, Lin et al. adopted a hysteresis observed control method [14]. Banning et al. built a hysteresis model for hysteresis displacement compensation [15]. There are some different models are used for hysteresis compensation such as the classical Preisach model [16], Inverse Preisach Model [17], Bouc-Wen model [18], and so on. The improvement of mathematical model compensation methods is limited. Thus, some studies using a compensator with a PID (proportional-integral-derivative) controller to improve the steady state error and dynamic tracking performance like $\mathrm{Ru}$ et al. proposed [19]. Beside mathematical compensation methods (e.g., feed-forward compensator), Liu et al. employed a capacitor in the piezoelectric driving circuit for hysteresis reduction and the method is called capacitor insertion method [2]. This study was concerned with positioning accuracy. Thus, only a PI (proportional-integral) controller was used.

There are three parameters which need to be taken into account in the design of a 2D circular flexure hinge: the minimum diameter $(b)$; the body height $(h)$; and the notch radius $(r)$, as shown in Figure 3. Estimating of the static performance of a z-tilt stage, such as coupling displacement and stage stiffness, can be made using simulation and stepwise displacement experiments. The dynamic performance of a $z$-tilt stage can be tested by a tracking experiment [2,20]. The first part of this study describes the use of the Taguchi method to optimize design of the circular flexure hinges. The second part is a description of dynamic performance tests of the proposed $z$-tilt stage. At the last in this study, some experiments were performed to check whether the results achieved the design intent.

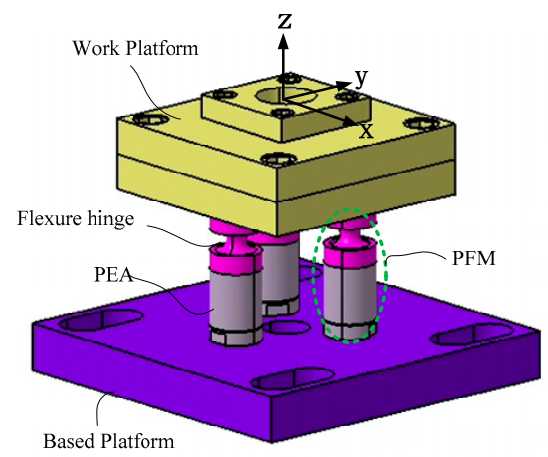

Figure 1. The simplest structure of a $z$-tilt stage. 

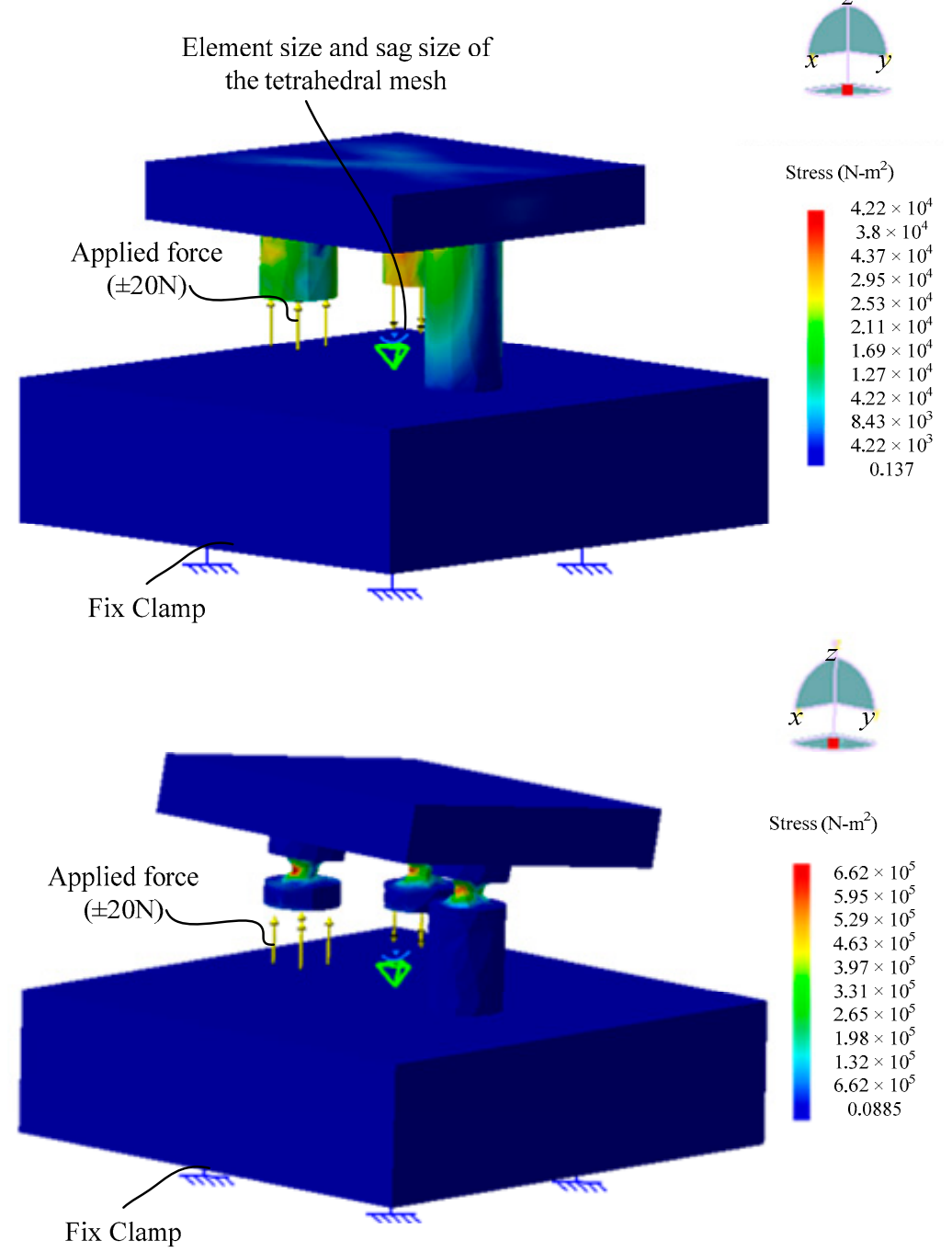

Figure 2. Simulation results of a $z$-tilt stage without (upper) and with (lower) flexure hinges.

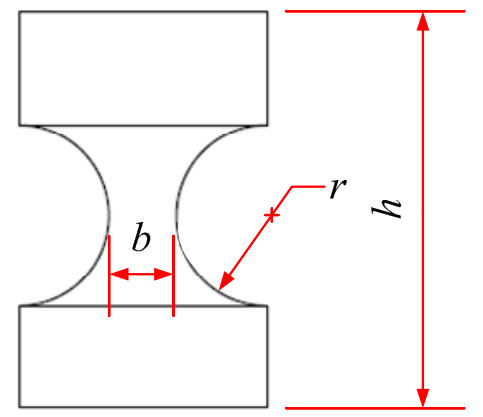

Figure 3. The important parameters for optimal circular flexure hinge design, the parameters including minimum diameter $(b)$, body height $(h)$ and notch radius $(r)$.

\section{Flexure Hinge Optimal Design}

The $\mathrm{S} / \mathrm{N}$ (signal-to-noise) ratio $\eta$ is used as a performance evaluation index for optimal design results obtained by the Taguchi method. In this study, quality characteristics include: (1) the smaller the better (STB), the ideal value being zero, such as the poisoning error of a machine tool; (2) the larger the better (LTB), the ideal value here being infinity, such as the lifetime of a device; and (3) nominally 
the best (NTB), the special value of a target, such as the wavelength of a laser interferometer. In this study, eight steps were followed to arrive at an optimal design for the 2D circular flexure hinges.

Step 1. Deciding the design parameters:

As previously mentioned, the three parameters this study is concerned with are the minimum diameter $(b)$, the body height $(h)$, and the notch radius $(r)$, as shown in Figure 3.

Step 2. Setting the parameter levels:

All parameters were set at three levels, as listed in Table 1, according to the required dimension of the stage, design experience, heuristics, machining rationality, notch sensitivity, and research results $[8,21]$. Please note, the optimal results based on level belong to local optimization, and are not global.

Table 1. The level values of each parameter ( $\mathrm{mm})$.

\begin{tabular}{cccc}
\hline Parameter & Minimal Diameter & Height & Notch Rad. \\
\hline Symbol & $b$ & $h$ & $r$ \\
\hline Level code & A & B & C \\
\hline Level 1 & 4 & 25 & 3 \\
Level 2 & 6 & 30 & 3.75 \\
Level 3 & 8 & 35 & 4.5 \\
\hline
\end{tabular}

Step 3. Building an orthogonal array:

In this study an $\mathrm{OA}_{9}\left(3^{3}\right)$ orthogonal array $(\mathrm{OA})$ was used in the simulation as shown in Table 2 where each level (A1, A2, A3, B1, .., C2, and C3) appears three times. The OA is balanced and there is no repeated permutation.

Table 2. The $\mathrm{OA}_{9}\left(3^{3}\right)$ orthogonal array.

\begin{tabular}{cccc}
\hline Trial $\backslash$ Parameter & A & B & C \\
\hline 1 & 1 & 1 & 1 \\
2 & 1 & 2 & 2 \\
3 & 1 & 3 & 3 \\
4 & 2 & 1 & 2 \\
5 & 2 & 2 & 3 \\
6 & 2 & 3 & 1 \\
7 & 3 & 1 & 3 \\
8 & 3 & 2 & 1 \\
9 & 3 & 3 & 2 \\
\hline
\end{tabular}

Step 4. Defining the output response:

Two output responses were defined for the evaluation index:

(1) Natural frequency $\left(\eta_{1}\right)$ : The natural frequencies of the $z$-tilt stage with no load and when loaded. For such a stage, the system bandwidth is usually proportional to the natural frequency and so the LTB equation was used for performance evaluation:

$$
\eta_{1}=-10 \times \log \left(\frac{1}{n} \sum_{i=1}^{n} \frac{1}{y_{i}{ }^{2}}\right)(\mathrm{dB})
$$

(2) Coupling angular displacement $\left(\eta_{2}\right)$ : The ideal value of coupling displacement is zero, so the STB equation was used for evaluation:

$$
\eta_{2}=-10 \times \log \left(\frac{1}{n} \sum_{i=1}^{n} y_{i}^{2}\right)
$$


In Equations (1) and (2), $y_{\mathrm{i}}$ represents the simulation output value, for example, the natural frequency (units can be ignored); $n$ represents the number of output response $\left(n=1\right.$ for $\eta_{1} ; n=1$ for $\left.\eta_{2}\right)$.

Step 5. Performing simulation:

Dassault Systèmes CATIA V5R15 was used for simulation in this study. For natural frequency simulation, this study used a $z$-tilt stage loading of zero and $5 \mathrm{~kg}$. For coupling angular displacement simulation, the $z$-tilt stage was rotated on the $y$-axis $\left(\theta_{y}\right)$ and observed the angular displacement of $x$-axis $\left(\theta_{x}\right)$. Please note that, for a $z$-tilt stage, coupling displacement for the $z$-direction motion is zero. Figure 4 shows the simulation setup and result, in which the applied force is $\pm 20 \mathrm{~N}$. The simulation results are shown in Tables 3 and 4 . Note that, since the stage is moved by constant force while simulation, displacement $\theta_{y}$ for each trail is different. This study is employed percentage for judging the simulation result.

Step 6. To compute the $\mathrm{S} / \mathrm{N}$ ratio:

According to Equations (1) and (2) and Table 3, the S/N ratio for each trial can be computed as shown in Table 5 . The average $\mathrm{S} / \mathrm{N}$ ratio denoted of $\bar{\eta}$, for example, for A1 and B2 are:

$$
\begin{gathered}
\bar{\eta} \text { for } \mathrm{A}_{1}: \bar{\eta}_{A 1}=\frac{(56.377)+(55.891)+(55.394)}{3}=55.887 \text {, and } \\
\bar{\eta} \text { for } \mathrm{B}_{2}: \bar{\eta}_{B 2}=\frac{(55.891)+(56.465)+(57.480)}{3}=56.612
\end{gathered}
$$

After computation, Tables 6 and 7 were built. In the tables, $\delta$ represents the maximum variation of average $\mathrm{S} / \mathrm{N}$ Ratio of a single influencing parameter, which can be computed using the following equation:

$$
\delta=\bar{\eta}_{\max }-\bar{\eta}_{\min }
$$

The value of $\delta$ also represents the degree of influence. A large value for $\delta$ means the parameter has more influence than others. For example, for a $z$-tilt stage the natural frequency and minimum diameter are the most important. Table 7 were constructed and ranking was made according to the degree of influence.

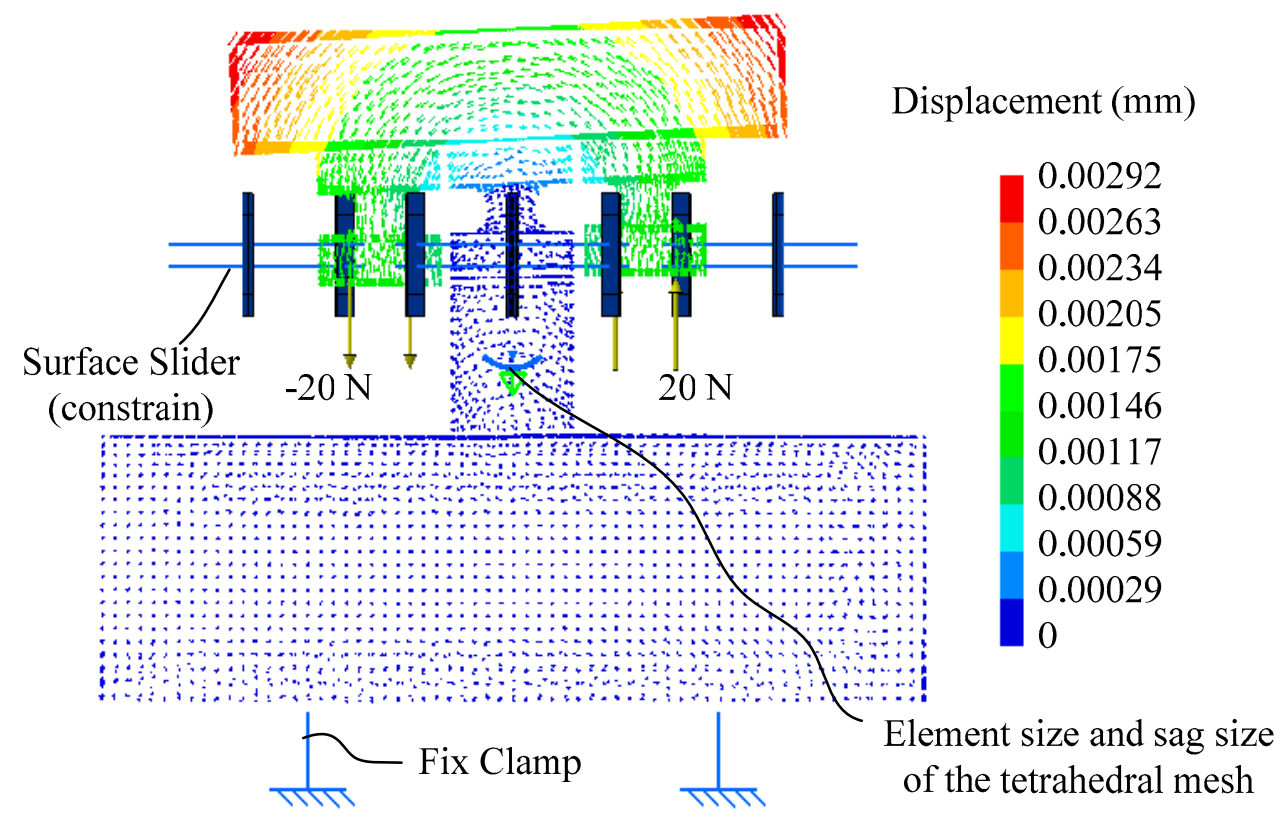

Figure 4. Simulation result for applied force of $\pm 20 \mathrm{~N}$, and the based stage is fix by the fix clamps as well as the flexure hinge constrained using the surface sliders (as an example). 
Table 3. Simulation results.

\begin{tabular}{|c|c|c|c|}
\hline \multirow[t]{2}{*}{ Trial } & \multicolumn{2}{|c|}{ Natural Frequency $(\mathrm{Hz})$} & \multirow{2}{*}{$\begin{array}{c}\text { Coupling Angular } \\
\text { Displacement (\%) } \\
\text { Percentage }\end{array}$} \\
\hline & No load & $5 \mathrm{~kg}$ load & \\
\hline 1 & 1143.25 & 510.24 & 1.02 \\
\hline 2 & 1080.58 & 482.50 & 4.89 \\
\hline 3 & 1018.74 & 455.83 & 8.57 \\
\hline 4 & 1246.49 & 555.45 & 1.79 \\
\hline 5 & 1154.19 & 515.47 & 1.71 \\
\hline 6 & 1126.61 & 506.3 & 1.77 \\
\hline 7 & 1408.27 & 626.49 & 0.03 \\
\hline 8 & 1294.4 & 579.64 & 0.11 \\
\hline 9 & 1218.48 & 546.85 & 0.32 \\
\hline
\end{tabular}

Table 4. Simulated Displacements of each trial.

\begin{tabular}{cccccc}
\hline Trial & $z$-Axis $(\mu \mathrm{m})$ & $\boldsymbol{x}$-Axis $(\mu \mathrm{m})$ & $\theta_{y}(\operatorname{arcsec})$ & $\theta_{x}(\operatorname{arcsec})$ & $\theta_{x} / \theta_{y}(\%)$ \\
\hline 1 & 2.9 & 1.9 & 12.07 & 0.12 & 1.02 \\
2 & 2.9 & 2.0 & 11.88 & 0.58 & 4.89 \\
3 & 2.6 & 2.0 & 10.75 & 0.92 & 8.57 \\
4 & 3.0 & 2.0 & 12.48 & 0.22 & 1.79 \\
5 & 2.9 & 2.1 & 12.11 & 0.21 & 1.71 \\
6 & 2.7 & 2.0 & 11.21 & 0.20 & 1.77 \\
7 & 3.0 & 2.0 & 12.32 & 0.00 & 0.03 \\
8 & 2.8 & 2.0 & 11.55 & 0.01 & 0.11 \\
9 & 3.0 & 2.3 & 12.32 & 0.04 & 0.32 \\
\hline
\end{tabular}

Table 5. S/N ratio calculation results (including orthogonal array).

\begin{tabular}{cccccc}
\hline Trial & A & B & C & $\begin{array}{c}\text { Natural Frequency } \\
(\mathbf{d B})\end{array}$ & $\begin{array}{c}\text { Coupling Angular Displacement } \\
\text { (dB) }\end{array}$ \\
\hline 1 & 1 & 1 & 1 & 56.377 & 59.828 \\
2 & 1 & 2 & 2 & 55.891 & 46.214 \\
3 & 1 & 3 & 3 & 55.394 & 41.340 \\
4 & 2 & 1 & 2 & 57.117 & 54.943 \\
5 & 2 & 2 & 3 & 56.465 & 55.340 \\
6 & 2 & 3 & 1 & 56.300 & 55.041 \\
7 & 3 & 1 & 3 & 58.164 & 90.458 \\
8 & 3 & 2 & 1 & 57.480 & 79.172 \\
9 & 3 & 3 & 2 & 56.971 & 69.897 \\
\hline
\end{tabular}

Table 6. S/N Ratio of natural frequency simulation results.

\begin{tabular}{cccc}
\hline Parameter & $\boldsymbol{b}$ & $\boldsymbol{h}$ & $\boldsymbol{r}$ \\
\hline Symbol & $\mathrm{A}$ & $\mathrm{B}$ & $\mathrm{C}$ \\
Level 1 & $55.887 \mathrm{~dB}$ & $57.219 \mathrm{~dB}$ & $56.719 \mathrm{~dB}$ \\
Level 2 & $56.627 \mathrm{~dB}$ & $56.612 \mathrm{~dB}$ & $56.660 \mathrm{~dB}$ \\
Level 3 & $57.538 \mathrm{~dB}$ & $56.222 \mathrm{~dB}$ & $56.674 \mathrm{~dB}$ \\
$\delta$ & $1.651 \mathrm{~dB}$ & $0.997 \mathrm{~dB}$ & $0.059 \mathrm{~dB}$ \\
Ranking & 1 & 2 & 3 \\
\hline
\end{tabular}


Table 7. S/N Ratio of coupling angular displacement simulation results.

\begin{tabular}{cccc}
\hline Parameter & $\boldsymbol{b}$ & $\boldsymbol{h}$ & $\boldsymbol{r}$ \\
\hline Symbol & $\mathrm{A}$ & $\mathrm{B}$ & $\mathrm{C}$ \\
Level 1 & $49.127 \mathrm{~dB}$ & $68.410 \mathrm{~dB}$ & $64.680 \mathrm{~dB}$ \\
Level 2 & $55.108 \mathrm{~dB}$ & $60.242 \mathrm{~dB}$ & $57.018 \mathrm{~dB}$ \\
Level 3 & $79.842 \mathrm{~dB}$ & $55.426 \mathrm{~dB}$ & $55.526 \mathrm{~dB}$ \\
$\delta$ & $30.715 \mathrm{~dB}$ & $12.984 \mathrm{~dB}$ & $9.154 \mathrm{~dB}$ \\
Ranking & 1 & 2 & 3 \\
\hline
\end{tabular}

Step 7. Deciding the optimal parameters:

From Tables 6 and 7, the optimal value of each parameter of the flexure hinge can be decided based on the following principium:

1. If the output responses of the experiments have the same trend, select the level with the highest $\mathrm{S} / \mathrm{N}$ ratio.

2. If the output responses of the experiments have no similar trend and have different ranking, select that with the lowest ranking.

3. If the output responses of the experiments have no similar trend and have same ranking, select the level with the highest $\mathrm{S} / \mathrm{N}$ ratio.

First, draw a cross-correlation chart from Tables 6 and 7 as shown in Figure 5. From this chart, find the optimal value for each parameter according to the above principium. For parameter A, the result satisfies principium 1, therefore, the optimization result of the minimum diameter is A3. For parameter $B$, the result also satisfies principium 1, thus, the optimization result of body height is B1. For parameter $C$, the result does not satisfy principium 1 or 2 , thus, principium 3 is used to select the optimal notch radius, in this study the choosing was C3. The optimal design parameters are listed in Table 8.

Step 8. Checking correctness of the results.

The optimal results of each parameter are A3, B1, and C3, which agrees exactly with trial 7 of the OA table. From Table 3, we can see that the natural frequency is highest and coupling angular displacement is the smallest of all the values in the OA table. Thus, the stage clearly complies with the required specifications and the output responses list in Table 9.

Table 8. Optimal circular flexure hinge design parameters.

\begin{tabular}{cccc}
\hline Parameter & Minimal Diameter & Body Height & Notch Radius \\
\hline Parameter & $b$ & $h$ & $r$ \\
Level value & $\mathrm{A} 3$ & $\mathrm{~B} 1$ & $\mathrm{C} 1$ \\
Optimal value & $8 \mathrm{~mm}$ & $25 \mathrm{~mm}$ & $4.5 \mathrm{~mm}$ \\
\hline
\end{tabular}

Table 9. Specifications of the z-tilt stage design (simulation result).

\begin{tabular}{ccc}
\hline & Output Response & Result \\
\hline \multirow{2}{*}{ Natural frequency } & No-load & $1408.27 \mathrm{~Hz}$ \\
\cline { 2 - 3 } & $5 \mathrm{~kg} \mathrm{load}$ & $626.49 \mathrm{~Hz}$ \\
\hline$\theta_{y}$ rotating & Coupling angular displacement of $\theta_{x}$ & $0.03 \%$ \\
\hline
\end{tabular}




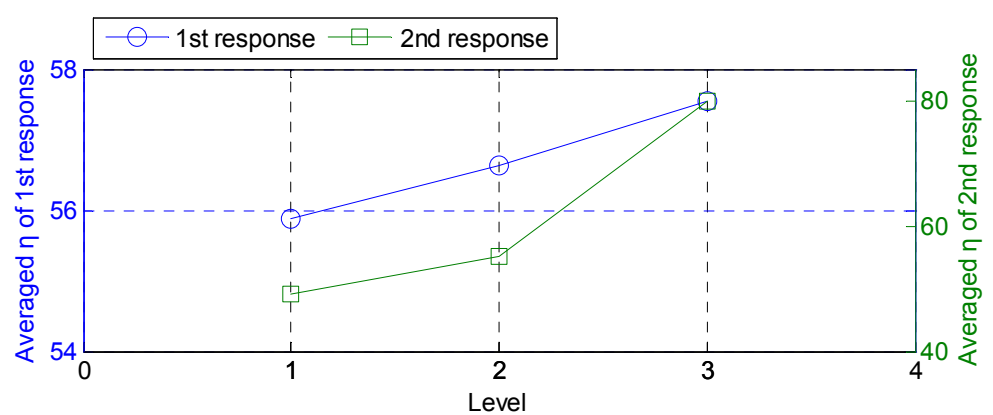

(a)

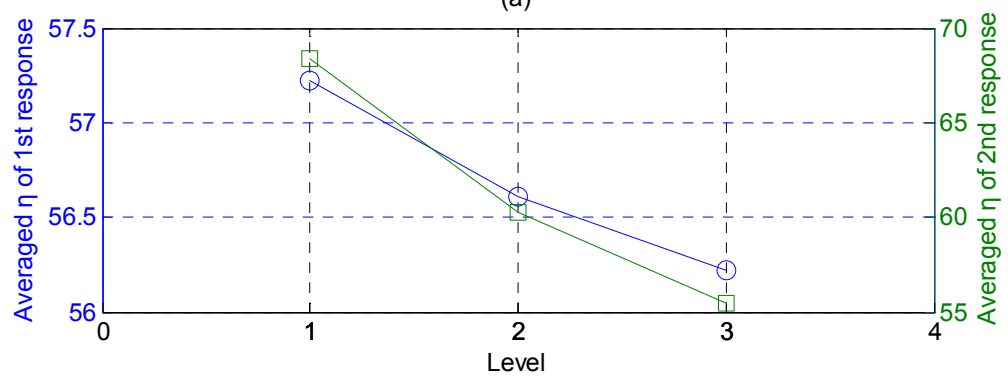

(b)

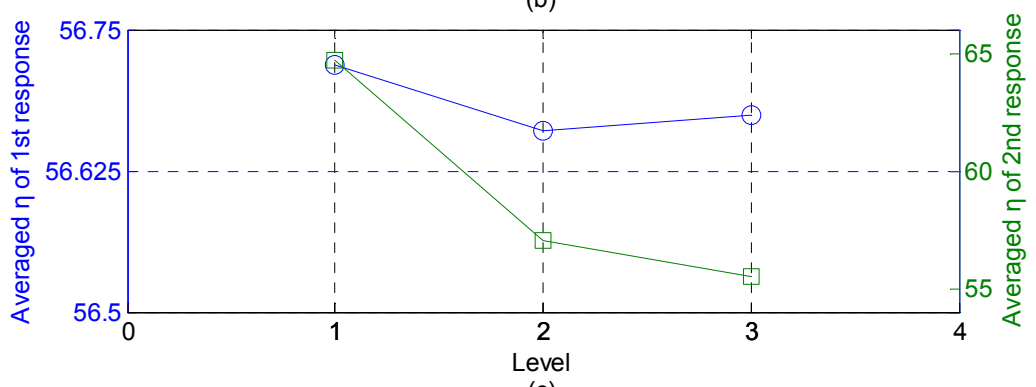

(c)

Figure 5. Parameters and levels cross-correlation charts: (a) Parameter A; (b) Parameter B; (c) Parameter C. 1st response is the natural frequency output, 2nd response is the coupling angular displacement.

\section{Kinematic Analysis}

The positions of the PFMs are shown in Figure 6. The mathematical model of the stage movement shows in Figure 7. The coordinate systems as seen in Figure 7 include: $\{R\}$ the reference coordinate system of the stage (the origin, or reference point), located at the center of the work platform; $\{\mathrm{Hi}\}$ represents the center position of the flexure hinge of the PFM, where $i=1,2$ and 3; and $\left\{\mathrm{R}^{\prime}\right\}$ represents the position of the reference point after the stage has moved. Let $\vec{s}=\left[\begin{array}{lll}s_{x} & s_{y} & s_{z}\end{array}\right]^{T}$ be the displacement vector of the $z$-tilt stage along the $x-, y$ - and $z$-axes, as well as $\theta_{x}$ and $\theta_{y}$ to be the angular displacement of the $z$-tilt stage. After the stage has moved, the center of the flexure hinge is moved to a new position and the coordinate system is denoted as $\{\mathrm{Hi}\}$. For example, (see Figure 8) when the reference point is moved from $\{R\}$ to $\left\{R^{\prime}\right\}$, the center position of the second flexure hinge is moved from $\{\mathrm{H} 2\}$ to $\left\{\mathrm{H} 2^{\prime}\right\}$, in which $\vec{\delta}_{i}=\left[\begin{array}{ccc}0 & 0 & \delta_{z i}\end{array}\right]$ represents the displacement vector of $i$-th piezoelectric actuator. Note that since the PFMs can only move along their $z$-axes, the vector components of the $x$ and $y$-axes are both zero. Assuming the distance and unity vector $d_{i}$ from $\{\mathrm{H} i\}$ to $\{\mathrm{R}\}$ is known, and $\vec{u}_{i}=\left[\begin{array}{lll}u_{i x} & u_{i y} & u_{i z}\end{array}\right]^{T}$, vector from $\{\mathrm{H} i\}$ to $\{\mathrm{R}\}$ is $\left|d_{i}\right| \vec{u}_{i}$, when the stage is rotated along the $x$ - and $y$-axes, the new unity vector denoted $\vec{u}_{i}$ can be computed by the following equation:

$$
\vec{u}_{i}^{\prime}=\left[\begin{array}{ccc}
1 & 0 & 0 \\
0 & \cos \theta_{x} & -\sin \theta_{x} \\
0 & \sin \theta_{x} & \cos \theta_{x}
\end{array}\right]\left[\begin{array}{ccc}
\cos \theta_{y} & 0 & \sin \theta_{y} \\
0 & 1 & 0 \\
-\sin \theta_{y} & 0 & \cos \theta_{y}
\end{array}\right] \vec{u}_{i} .
$$


From Figure 8, the movement equation of the $z$-tilt stage can be derived as:

$$
\vec{s}=\left|d_{i}\right| \vec{u}_{i}+\vec{\delta}_{i}-\left|d_{i}\right| \vec{u}_{i}^{\prime}
$$

where the unity vectors are:

$$
\vec{u}_{i}=\left[\begin{array}{lll}
u_{i x} & u_{i y} & u_{i z}
\end{array}\right]^{T}=\left[\begin{array}{lll}
\frac{d_{i x}}{\sqrt{d_{i x}^{2}+d_{i y}^{2}+d_{i z}^{2}}} & \frac{d_{i y}}{\sqrt{d_{i x}^{2}+d_{i y}^{2}+d_{i z}^{2}}} & \frac{d_{i z}}{\sqrt{d_{i x}^{2}+d_{i y}^{2}+d_{i z}^{2}}}
\end{array}\right] .
$$

After expanding, Equation (6) can be written as:

$$
\left\{\begin{array}{l}
s_{x}=\left|d_{i}\right|\left(u_{i x}-u_{i x} \cos \theta_{y}-u_{i z} \sin \theta_{y}\right) \\
s_{y}=\left|d_{i}\right|\left(u_{i y}-u_{i y} \cos \theta_{y}-u_{i x} \sin \theta_{y} \sin \theta_{y}+u_{i z} \sin \theta_{y} \cos \theta_{y}\right) \\
s_{z}=\delta_{z i}+\left|d_{i}\right|\left(u_{i z}-u_{i y} \sin \theta_{x}+u_{i x} \cos \theta_{y} \sin \theta_{y}-u_{i z} \cos \theta_{y} \cos \theta_{y}\right)
\end{array}\right.
$$

For a nano-scale $z$-tilt compensation stage, the angular displacement is much smaller than one degree, thus Equation (8) can be linearized and simplified as below:

$$
\left\{\begin{array}{l}
s_{x}=-\left|d_{i}\right| u_{i z} \theta_{y} \\
s_{y}=\left|d_{i}\right| u_{i z} \theta_{x} \\
s_{z}=\delta_{z i}+\left|d_{i}\right|\left(u_{i x} \theta_{y}-u_{i y} \theta_{x}\right)
\end{array} .\right.
$$

From Equation (9), it can be seen that when the stage is rotated along $x$ - and $y$-axes, coupling displacement will occur in the z-axis. In this study, $\left|d_{i}\right|$ is much smaller than 1 meter (57.306 mm), the angular displacements of $\theta_{x}$ and $\theta_{y}$ are much smaller than 1 degree as well as $u_{i z}$ being smaller than 1 . In other words, the coupling displacements of $s_{x}$ and $s_{y}$ are very small and can be ignored. This means the relationship between the actuators and the stage displacements can be written as:

$$
\left[\begin{array}{l}
\delta_{z 1} \\
\delta_{z 2} \\
\delta_{z 3}
\end{array}\right]=\left[\begin{array}{lll}
1 & \left|d_{1}\right| u_{1 y} & -\left|d_{1}\right| u_{1 x} \\
1 & \left|d_{2}\right| u_{2 y} & -\left|d_{2}\right| u_{2 x} \\
1 & \left|d_{3}\right| u_{3 y} & -\left|d_{3}\right| u_{3 x}
\end{array}\right]\left[\begin{array}{c}
s_{z} \\
\theta_{x} \\
\theta_{y}
\end{array}\right]
$$

Because of $d_{i z}=d_{z}$, Equation (10) can be rewritten as:

$$
\left[\begin{array}{l}
\delta_{z 1} \\
\delta_{z 2} \\
\delta_{z 3}
\end{array}\right]=\left[\begin{array}{lll}
1 & d_{1 y} & -d_{1 x} \\
1 & d_{2 y} & -d_{2 x} \\
1 & d_{3 y} & -d_{3 x}
\end{array}\right]\left[\begin{array}{l}
s_{z} \\
\theta_{x} \\
\theta_{y}
\end{array}\right]=\mathbf{M} \cdot \vec{\psi}
$$

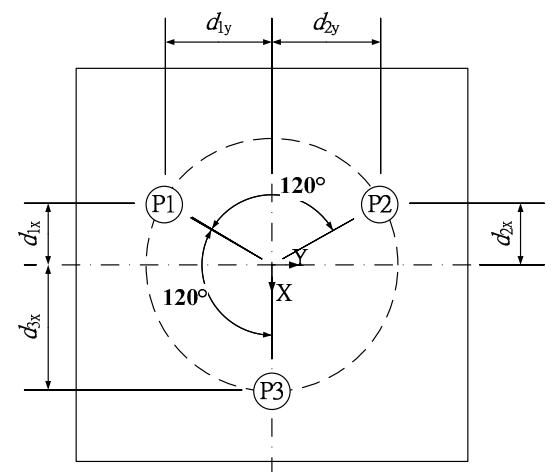

Figure 6. Install position of each PFM, in which Pi represents $i$-th PFM, $\mathrm{d}_{\mathrm{ix}}$ and $\mathrm{d}_{\mathrm{i} y}$ represented the distance from the stage center line to the center of $i$-th PFM at $x$ - and $y$-axes. 


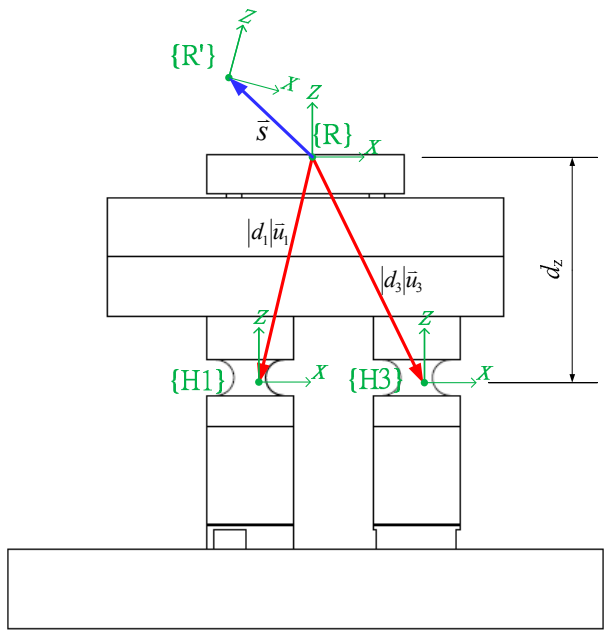

(a)

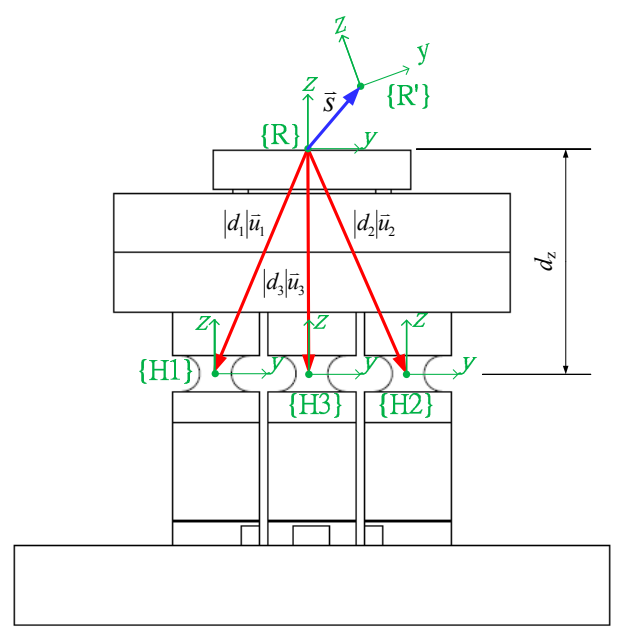

(b)

Figure 7. $z$-tilt stage movement vector analyze model. (a) $x z$ plane (b) $y z$ plane. In the figure, vector $\vec{s}$ is the displacement vector of the working platform from $\{R\}$ moving to $\left\{R^{\prime}\right\} ; d_{z}$ is the height between the surface of the working platform to the rotation center of the flexure hinges; the vectors $\left|d_{i}\right| \vec{u}_{i}$ is the distance vector from $\{\mathrm{R}\}$ to $\{\mathrm{H} i\}$ for $i$-th PFM and $i=1,2,3$.

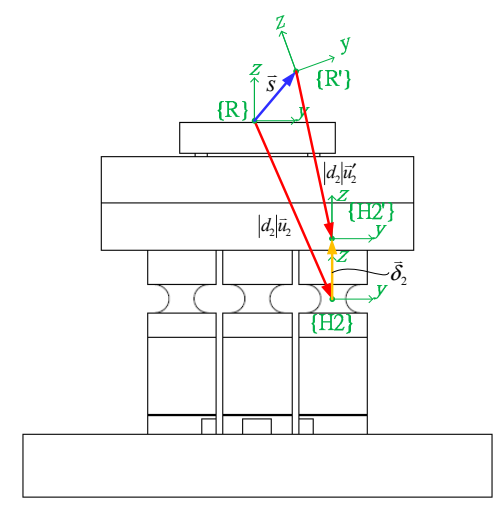

Figure 8. When the stage undergoes $z$-tilt motion, the center position of the flexure hinge is changed from $\{\mathrm{H} 2\}$ to $\left\{\mathrm{H}^{\prime}\right\}$. In the figure, vector $\vec{s}$ is the displacement vector of the working platform from $\{\mathrm{R}\}$ moving to $\left\{\mathrm{R}^{\prime}\right\}$; vector $\vec{\delta}_{2}$ is displacement vector of PFM2 at $z$-direction; the vectors $\left|d_{2}\right| \vec{u}_{2}$ is the distance vector from $\{\mathrm{R}\}$ to $\{\mathrm{H} 2\} ;\left|d_{2}\right| \vec{u}_{2}^{\prime}$ is the distance vector from $\left\{\mathrm{R}^{\prime}\right\}$ the $\left\{\mathrm{H} 2^{\prime}\right\}$ after the working platform moved.

\section{Experimental Result}

\subsection{Subsection}

The center positions of each PFM are listed in Table 10 and the distance from each reference point to the center of each flexure hinge is $\left|d_{1}\right|=\left|d_{2}\right|=\left|d_{3}\right|=57.306 \mathrm{~mm}$. The unity vectors from

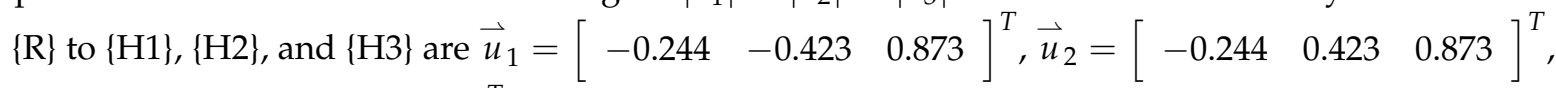
and $\vec{u}_{3}=\left[\begin{array}{lll}0.488 & 0 & 0.873\end{array}\right]^{T}$ respectively. Since the rotating center of the z-tilt stage is not on the reference point, $x$ - and $y$-axis coupling displacement exists only when the stage is rotated. Figure 9 shows the simulation result derived from Equation (8). 
Table 10. List of the position of each PFM (unit: $\mathrm{mm}$ ).

\begin{tabular}{cccc}
\hline PFMs Center Position & $x$ & $y$ & $z$ \\
\hline PFM1 & -14.000 & -24.249 & 50.000 \\
PFM2 & -14.000 & 24.249 & 50.000 \\
PFM3 & 28.000 & 0.000 & 50.000 \\
\hline
\end{tabular}

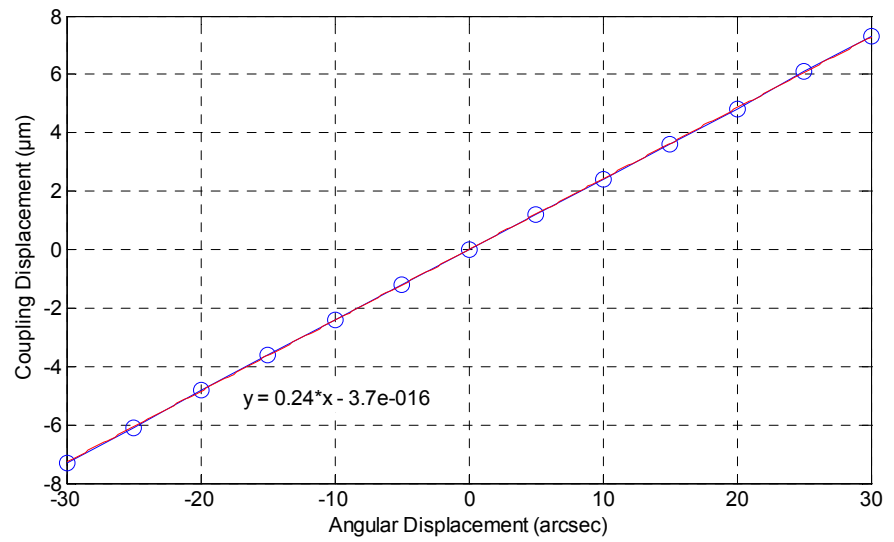

Figure 9. Coupling displacement simulation result. During simulation, the angular displacement of the $z$-tilts was set to \pm 30 arcsec, and the coupling displacement was calculated using Equation (8).

\subsection{Control of Stage Positioning}

In this study, displacement of the z-tilt stage was measured using a Renishaw RLE10 laser interferometer and a Hamamatsu S4349 quadrant Si PIN photodiode (QPD). The QPD was used to measure the tilt angle using the principle of auto-collimation. The measurement principle can refer to the previous studies $[2,20]$. Angle measurement resolution was about $0.1 \mathrm{arcsec}$, the measurement error being smaller than 0.25 arcsec after calibration. The piezoelectric actuator and signal amplifier used was an HPSt 150/14-10/12 VS22 and a PST 150/10/60 VS18. The stroke of the piezoelectric actuators used was $16 \mu \mathrm{m}$. The angular displacement of tilt motion of the stage is about \pm 30 arcsec. The signal was acquired using dSpace CP1103. The stage control following diagram (Figure 10) shows the inclusion of a PI controller and a feed-forward compensator [22]. The experimental setup is shown in Figure 11. In this study, minimum stepwise tests were performed to figure out the stage positioning resolution. Figure 12 shows the results of test positioning of the $z$-tilt stage at $20 \mathrm{~nm}$ and 0.1 arcsec. Signal noise can also be determined in the stepwise tests.

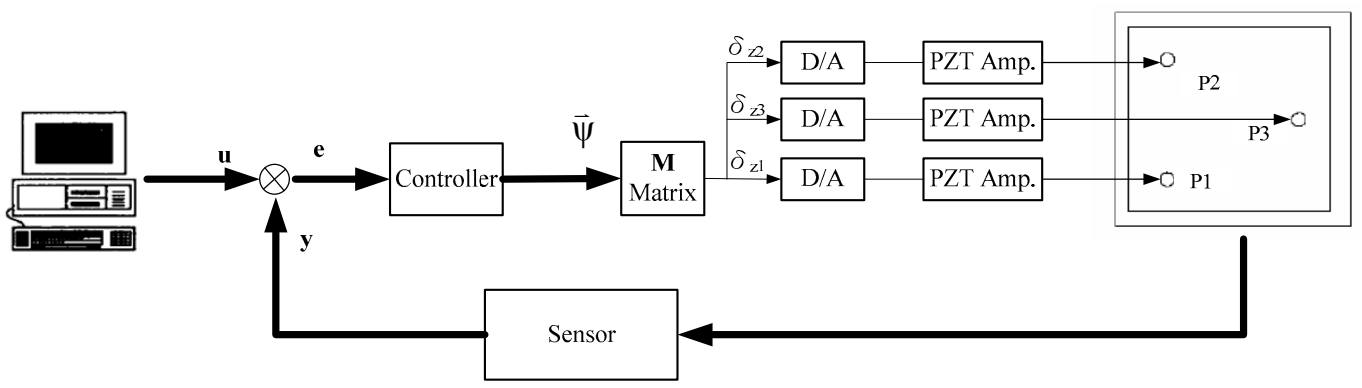

Figure 10. Stage control following diagram. In the figure, ' $\mathbf{u}$ ' represents the control command; ' $y$ ' represents the measured displacement; 'e' represents position error which equals $\mathrm{u}-\mathrm{y}$; vector $\vec{\psi}$ and matrix $\mathbf{M}$ are the stage displacement vector and stage-PFM displacement converting matrix, respectively as seen Equation (11); $d_{z i}$ is the displacement value of $i$-th PFM; PZT-Amp. is signal amplifier of the piezo-electric actuator; $\mathrm{P}_{i}$ represents $i$-th PFM. 


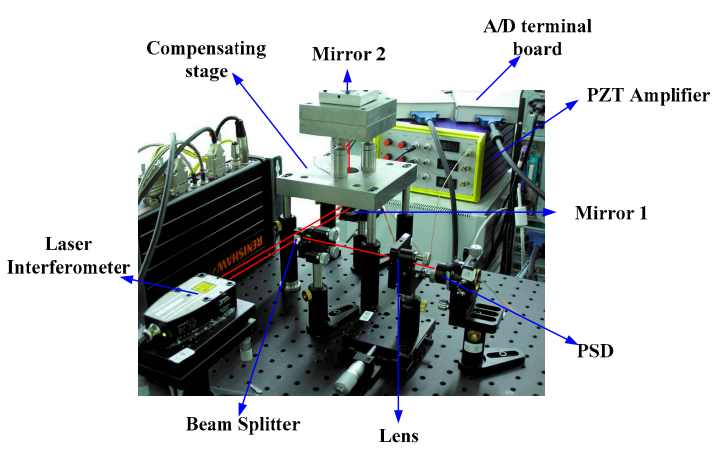

Figure 11. The experimental setup.

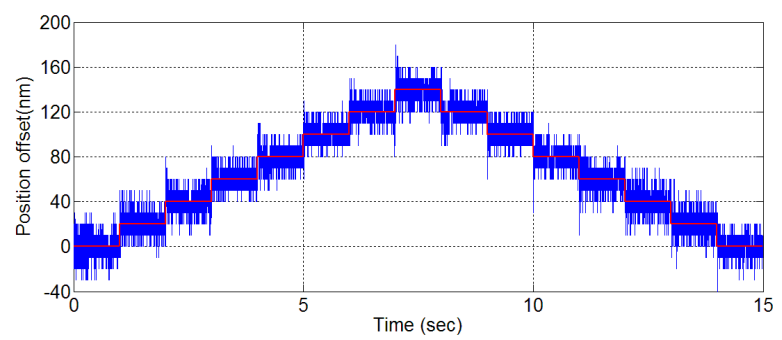

(a)

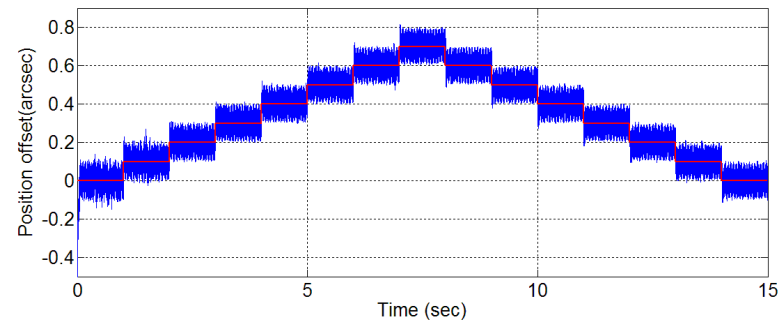

(b)

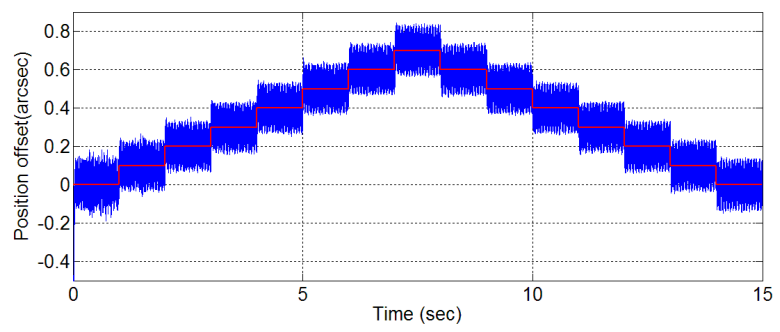

(c)

Figure 12. Stage resolution experiment results: (a) z-axis movement; (b) $\theta_{\mathrm{x}}$ movement; (c) $\theta_{\mathrm{y}}$ movement.

Because the evaluation index of the optimal design of the flexure hinge relies on coupling displacement and natural frequency, the following experiment was used as a check. Figure 13 shows coupling displacement experiment result. The tracking signal is a sine wave with $1 \mathrm{~Hz}$ frequency and \pm 5 arcsec amplitude. The stage is controlled in closed loop with sampling rate of $800 \mathrm{~Hz}$. When giving the stage a sine wave command for $\theta_{y}$ only, the time response is shown in Figure 13b,c. The result shows the coupling displacement of the $z$-axis and $\theta_{x}$ are about $300 \mathrm{~nm}$ and $1 \mathrm{arcsec}$. This is better than the result obtained by simulation. The natural frequency of the stage was determined by an impulse response experiment [14] and the Results are shown in Figure 14. The Natural frequency is about $510 \mathrm{~Hz}$. This value is lower than that obtained by simulation. 


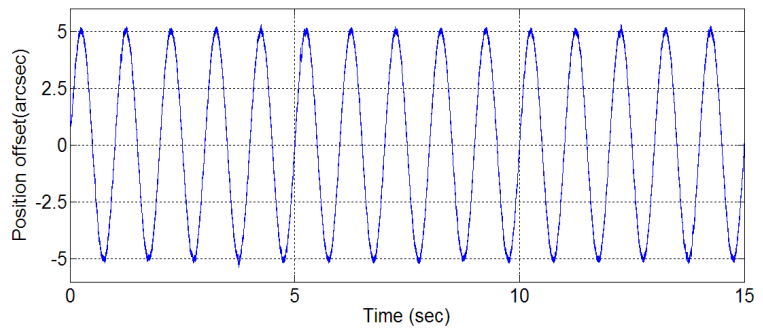

(a)

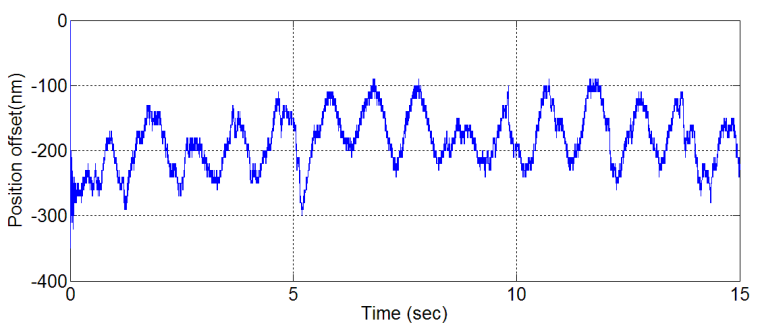

(b)

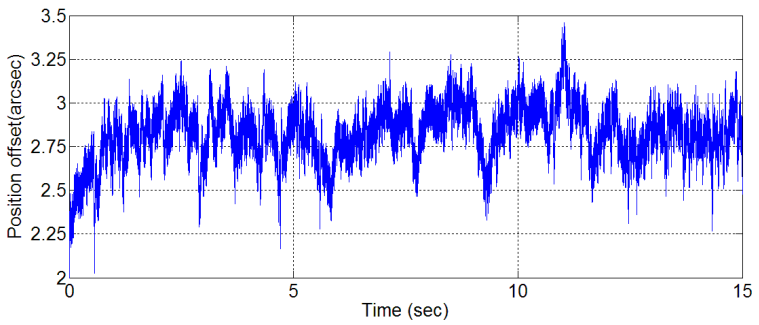

(c)

Figure 13. Coupling displacement experiment results: (a) $\theta_{\mathrm{y}}$ movement command, a sine wave of $1 \mathrm{~Hz}$ and amplitude 5 arcsec; (b) time response of $z$-axis movement; (c) time response of $\theta_{\mathrm{x}}$ movement.
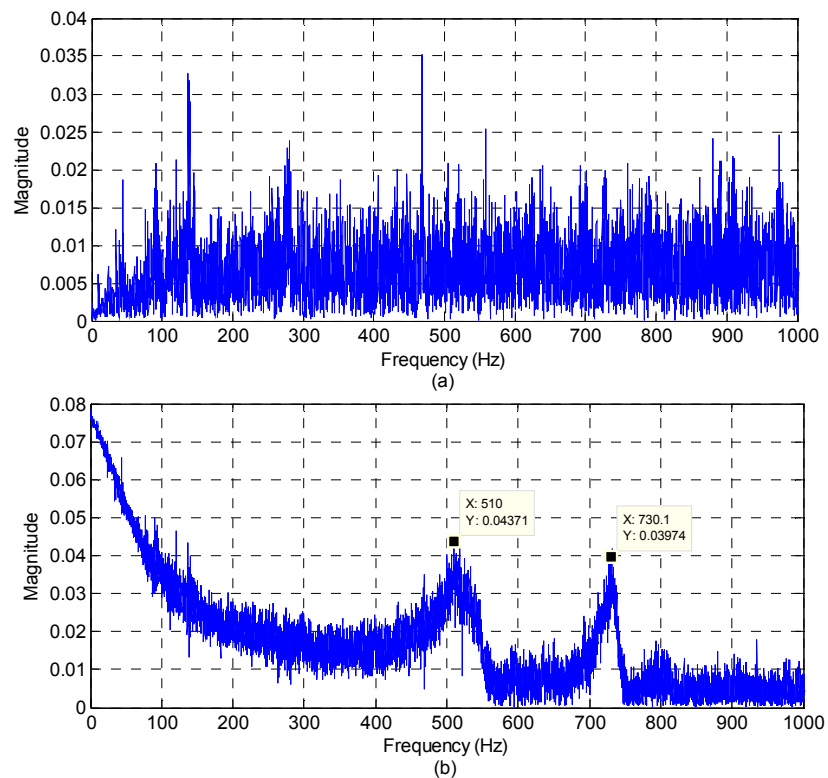

Figure 14. Stage impulse response experiment results: (a) frequency response of the stage before the impulse test (signal noise); (b) frequency response of the stage when an impulse was input to the stage. 


\section{Conclusions}

In this study, an eight step Taguchi procedure was used to design a circularity flexure hinge for a nano-scale $z$-tilt piezoelectric actuator based stage. The most important design parameters that effect stage performance, natural frequency, and coupling displacement, are minimum diameter, body height, and notch radius. The results show that the minimum diameter of the circularity flexure hinge is the most important design parameter. The simulation results also show that the flexure hinge influences stage coupling displacement more than natural frequency, and a smaller minimum diameter will give less coupling displacement, but will decrease stage bandwidth and stiffness. Simulation and experimental comparison table shows in Table 11. The stage natural frequency can be determined by its impulse response and found a natural frequency of $510 \mathrm{~Hz}$ and coupling displacement of $300 \mathrm{~nm}$ for $z$-axis, 1 arcsec for $\theta_{x}$ the stage tracked a sine wave of $1 \mathrm{~Hz}$ and an amplitude of 5 arcsec on $\theta_{y}$. The natural frequency of the experimental result is a little lower than in the simulation. This might be because the stiffness of the piezoelectric actuator structure is not an object like that in the CATIA simulation. The actuators are made of solid piezoelectric modules, a steel housing, a rubber o-ring, and a cover. The actual physical structure of the piezoelectric actuators is looser and not so stiff as it is in the simulation.

Table 11. Comparison between the simulation and experimental results.

\begin{tabular}{cccc}
\hline & Output Response & \multicolumn{2}{c}{ Result } \\
\hline \multirow{2}{*}{ Natural frequency } & No-load & $1408.27 \mathrm{~Hz}$ & $*$ \\
\cline { 2 - 4 } & $5 \mathrm{~kg}$ load & $626.49 \mathrm{~Hz}$ & $510 \mathrm{~Hz}$ \\
\hline$\theta_{y}$ rotating & Coupling angular displacement of $\theta_{x}$ & $0.032 \%$ & $20 \%$ \\
\hline
\end{tabular}

Note: * The natural frequency could not be measured due to the mirror used to reflect the laser ray was installed on the $5 \mathrm{~kg}$ mount.

Acknowledgments: This work was supported by the Ministry of Science and Technology, Taiwan.

Conflicts of Interest: The author declare no conflicts of interest.

\section{References}

1. Lee, C.-W.; Kim, S.-W. An ultraprecision stage for alignment of wafers in advanced microlithography. Precis. Eng. 1997, 21, 113-122. [CrossRef]

2. Liu, C.-H.; Chen, C.-L.; Lee, H.-W.; Jywe, W.-Y. Improvement of the nonlinear dynamic response of a $z$-tilts lead zirconate titanate-based compensation stage using the capacitor insertion method. Rev. Sci. Instrum. 2009, 80, 1151-1065. [CrossRef] [PubMed]

3. Polit, S.; Jingyan, D. Development of a high-bandwidth XY nanopositioning stage for high-rate micro-/nanomanufacturing. IEEE/ASME Trans. Mechatron. 2011, 16, 724-733. [CrossRef]

4. Chen, C.-M.; Hsu, Y.-C.; Fung, R.-F. System identification of a scott-russell amplifying mechanism with offset driven by a piezoelectric actuator. Appl. Math. Model. 2012, 36, 2788-2802. [CrossRef]

5. Ahuett-Garza, H.; Chaides, O.; Garcia, P.N.; Urbina, P. Studies about the use of semicircular beams as hinges in large deflection planar compliant mechanisms. Precis. Eng. 2014, 38, 711-727. [CrossRef]

6. Tian, Y.; Shirinzadeh, B.; Zhang, D.; Zhong, Y. Three flexure hinges for compliant mechanism designs based on dimensionless graph analysis. Precis. Eng. 2010, 34, 92-100. [CrossRef]

7. Tian, Y.; Shirinzadeh, B.; Zhang, D. Closed-form compliance equations of filleted V-shaped flexure hinges for compliant mechanism design. Precis. Eng. 2010, 34, 408-418. [CrossRef]

8. Ha, J.-L.; Kung, Y.-S.; Hu, S.-C.; Fung, R.-F. Optimal design of a micro-positioning scott-russell mechanism by taguchi method. Sens. Actuator A Phys. 2006, 125, 565-572. [CrossRef]

9. Dao, T.-P.; Huang, S.-C. Robust design for a flexible bearing with 1-DOF translation using the taguchi method and the utility concept. J. Mech. Sci. Technol. 2015, 29, 3309-3320. [CrossRef]

10. Ouyang, P.R. A spatial hybrid motion compliant mechanism: Design and optimization. Mechatronics 2011, 21, 479-489. [CrossRef] 
11. Pahk, H.J.; Lee, D.S.; Park, J.H. Ultra precision positioning system for servo motor-piezo actuator using the dual servo loop and digital filter implementation. Int. J. Mach. Tools Manuf. 2001, 41, 51-63. [CrossRef]

12. Jywe, W.-Y.; Jeng, Y.-R.; Liu, C.-H.; Teng, Y.-F.; Wu, C.-H.; Wang, H.-S.; Chen, Y.-J. A novel 5DOF thin coplanar nanometer-scale stage. Precis. Eng. 2008, 32, 239-250. [CrossRef]

13. Woronko, A.; Huang, J.; Altintas, Y. Piezoelectric tool actuator for precision machining on conventional CNC turning centers. Precis. Eng. 2003, 27, 335-345. [CrossRef]

14. Lin, C.-J.; Yang, S.-R. Precise positioning of piezo-actuated stages using hysteresis-observer based control. Mechatronics 2006, 16, 417-426. [CrossRef]

15. Banning, R.; de Koning, W.L.; Adriaens, H.J.M.T.A.; Koops, R.K. State-space analysis and identification for a class of hysteretic systems. Autom 2001, 37, 1883-1892. [CrossRef]

16. Ping, G.; Musa, J. Tracking control of a piezoceramic actuator. IEEE Trans. Control Syst. Technol. 1996, 4, 209-216. [CrossRef]

17. Song, G.; Jinqiang, Z.; Xiaoqin, Z.; Abreu-Garcia, J.A.D. Tracking control of a piezoceramic actuator with hysteresis compensation using inverse preisach model. IEEE/ASME Trans. Mechatron. 2005, 10, 198-209. [CrossRef]

18. Hurtado, J.E.; Barbat, A.H. Equivalent linearization of the bouc-wen hysteretic model. Eng. Struct. 2000, 22, 1121-1132. [CrossRef]

19. Ru, C.; Sun, L. Improving positioning accuracy of piezoelectric actuators by feedforward hysteresis compensation based on a new mathematical model. Rev. Sci. Instrum. 2005, 76. [CrossRef]

20. Liu, V.-T.; Liu, C.-H.; Chen, T.-Y.; Lin, C.-L.; Lin, Y.-C. Tracking control of the $z$-tilts error compensation stage of the nano-measuring machine using capacitor insertion method. Adv. Intell. Comput. Theor. Appl. 2007, $4681,616-625$.

21. Friedrich, R.; Lammering, R.; Heurich, T. Nonlinear modeling of compliant mechanisms incorporating circular flexure hinges with finite beam elements. Precis. Eng. 2015, 42, 73-79. [CrossRef]

22. Zhuang, G.-Y.; Lee, H.-W.; Liu, C.-H. Determination of the position and orientation of a flat piezoelectric micro-stage by moving the optical axis. Rev. Sci. Instrum. 2014, 85. [CrossRef] [PubMed]

(C) 2016 by the author; licensee MDPI, Basel, Switzerland. This article is an open access article distributed under the terms and conditions of the Creative Commons Attribution (CC-BY) license (http://creativecommons.org/licenses/by/4.0/). 